\title{
Modeling Multi-Echelon Multi-Supplier Repairable Inventory Systems with Backorders
}

\author{
Yael Perlman, Ilya Levner \\ Department of Management, Bar-Ilan University, Ramat-Gan, Israel. \\ Email: perlmay@mail.biu.ac.il \\ Received July $20^{\text {th }}, 2010$; revised September $12^{\text {th }}, 2010$; accepted October $19^{\text {th }}, 2010$.
}

\begin{abstract}
This paper considers an inventory system responsible for repairable equipments located at several operational sites, each in different area. When a failure occurs at the operational site, spare parts are required. We analyze a multiple-supplier inventory system that includes an internal repair shop that offers several modes of repair with different repair times and an external supplier of spare parts. The network model of the problem presented here efficiently solves the problem for deterministic demands that vary over time with backorders taken into account.
\end{abstract}

Keywords: Multi-Supplier, Repairable Inventory Systems, Network Flow Model, Spare Parts Networks

\section{Introduction}

Inventory systems where units which fail are repaired at a repair shop, rather than discarded, are called repairable-item inventory systems. A repairable spare part network implies the existence of locations where spare parts are stocked as well as facilities to repair failed items. Many organizations extensively use multi-echelon repairable-item inventory systems to support advanced computer systems and sophisticated medical and military equipment [1-4].

In this paper, we assume a multi-echelon inventory system with several operational sites (the bases) and two supply modes: an external supplier and a repair shop (the depot). We analyze a repair shop with two modes of repair: one with a normal repair time; the other with an expedited repair time. When a failure at the operational sites occurs, we assume a demand appears for a spare part. If the stock required to fulfill this demand is insufficient on a certain day, the unfulfilled demand is backordered. The backorder is fulfilled later when new items arrive from an external supplier or when the repair shop fixes the failed item. The expected number of backorders as well as the backorder costs and the number of backorder days are important measures of the effectiveness of the inventory management. The motivation of our study is to develop a model for planning and predicting how many spare parts must be purchased from the external supplier and how many failed items need to be repaired, at either the fast, expedited track or the regular track, in order to achieve minimum operating costs.

The literature about spare parts inventory models is extensive. In a recent survey, Minner [5] reviewed inventory models with multiple supply options. Although most of the literature is dedicated to multi-echelon distribution systems where relationships between a single vendor and a single buyer or a single vendor and multiple buyers are analyzed, there are number of papers that deal with multi-echelon multi-supplier systems. Aggarwal and Moinzadeh [6], Moinzadeh and Aggarwal [7]), Alfredsson and Verrijdt [8] and Ganeshan [9] analyzed multiple distribution or production options which have different lead times. Hausman and Scudder [2], Pyke [10], Verrijdt et al. [11], Perlman et al. [3], Sleptchenko et al. [4-12], Perlman and Kaspi [13] and recently Adan et al. [1] studied multi-echelon inventory systems with several repair modes. All the above models are steady-state models which assume that failures occur according to a Poisson process with a constant rate.

A different stream of literature (e.g., Abdul-Jalbar et al. [14] and Federgruen et al. [15]) focuses on studying the models where demands are predictable and deterministic. Following this line of research, in this paper we assume that demand forecast in the forthcoming period is known. This allows us to find an optimal solution when demand for spare parts can be estimated in advance for every day of the planning period. The solution methodology used in this paper extends and develops early deterministic 
spare-part management models. This approach, which is known in the literature as the caterer model has been discussed by Prager [16], Ford and Fulkerson [17], and Gass [18], who have suggested to model complex problem properties using dynamic networks. Today modeling of dynamic processes in production, maintenance and transportation with the help of dynamic networks is one of the fundamental pillars for material service and management in supply chain systems (see, e.g., Lee and Billigton [19]. Watts and Strogatz [20], Liu et al. [21], Liu and Zhang [22], and Zheng [23]).

Based on the dynamic network design, our model has three main features. First, assuming demands to be deterministic and predictable, we formulate a mathematical network-flow model for optimizing the circulation of spare parts and assigning repair priorities. Second, we explicitly introduce transportation times and costs for shipments and deliveries as well as backorder times and penalties. And third, our approach makes it possible to implement an on-line the what-if analysis, providing optimal stock flows and optimal priorities for different values of interior and exterior stocks, transportation delays and changing costs.

\section{Model}

In this section we describe the spare part supply system, introduce the parameters and variables and show how the objective function and the constraints are calculated.

\subsection{System Description}

We consider several operational sites (bases) served by one repair shop (depot) with a storage facility where spares are kept. Depot stock can also be filled from an external supplier (see Figure 1).

When a failure occurs at the base, if there is stock at the depot storage a replacement item is sent through the out pipeline in order to meet the base requirement for spare parts. Otherwise there is a backorder. This backorder will last until a spare part arrives from the depot (after it was repaired) or from an external supplier. The failed item is sent to the depot for repair through the in-pipeline. The depot has two modes of repair service: normal, in which items are repaired at a "slow" rate and an expedited process, in which items are repaired at a faster rate. The expedited repair service is more expensive since there are increased manpower costs whether in hiring additional personnel or paying existing personnel to work additional shifts. We assume that after the repair is completed, the item is as good as new and the repaired item either becomes part of the depot spare stock or fills a backorder if one exists. No distinction is made between a repaired item deriving from the fast or slow service and a new item that has been purchased from an external supplier: they all became part of the depot stock. We assume that there is infinite repair capacity at the depot and that the depot can repair every failed item. Items may also be purchased from an external supplier and sent to the depot through the purchase pipeline. The price of a new item is much higher then the repair costs.

\subsection{Notations and Variables}

Let an integer $T$ denote the planning period $(t=1, \ldots, T)$; $K$ the number of bases $(k=1, \ldots, K)$; and $I$ the repair modes ( $i=1$ fast repair, $i=2$ slow repair).

The following parameters are assumed to be given input data:

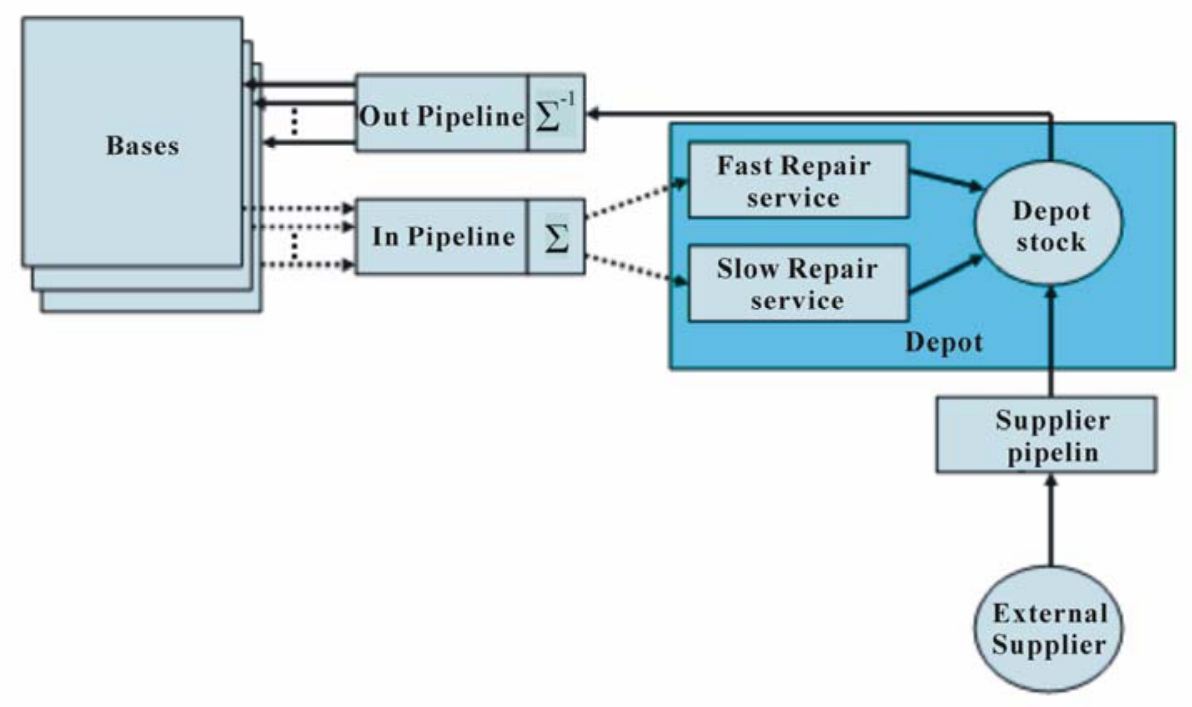

Figure 1. Flow of parts in the multi-echelon system. 
$R_{t}(k)$ : the required number of good items on day $t$ in base $k$

$F_{t}(k)$ : the entering flow of failed items on day $t$ in base $k$ $n$ : shipping time at the in pipeline

$m$ : shipping time at the out pipeline

$l$ : lead time from external supplier to the depot

$p$ : repair time at slow repair service

$q$ : repair time at fast repair service $(q<p)$

$c$ : cost charged for transporting a unit item

$e$ : cost charged for buying a new unit item

$a_{i}$ : cost charged for repairing a unit item at depot services i $\left(e>a_{1}>a_{2}\right)$

$h$ : inventory holding cost per unit item

$d$ : cost charged for distributing a unit item

$b$ : penalty cost for per unit backordered

We introduce the following (integer) variables:

$0 \leq q_{t}(k)$ : the number of failed items sent from base $k$ on day $t$

$0 \leq l_{t}(k)$ : the number of failed items left unsent at base $k$ on day $t$

$0 \leq Q_{t}(k)$ : the flow of failed items that arrived at the depot from base $k$ on day $t$

$0 \leq D S_{t}$ : the depot stock of good items on day $t$

$0 \leq x_{t}$ : the number of items entering the fast repair service at the depot on day $t$

$0 \leq y_{t}$ : the number of items entering the slow repair service at the depot on day $t$

$0 \leq X_{t}$ : the number of items repaired at the fast repair service in the depot on day $t$

$0 \leq Y_{t}$ : the number of items repaired at the slow repair service in the depot on day $t$

$0 \leq u_{t}$ : the number of items ordered from external supplier on day $t$

$0 \leq U_{t}$ : the number of items that arrived at the depot stock from supplier on day $t$

$0 \leq S_{t}$ : the number of good items sent from the depot on day $t$

$0 \leq z_{t}$ : the number of good items sent from depot to base $k$ on day $t$

$0 \leq Z_{t}(k)$ : the number of good items that arrived to base $k$ on day $t$

$0 \leq B O_{t}(k) i$ : the number of backordered demands at base $k$ on day $t$

\subsection{Mathematical Modeling Framework}

Our objective is to minimize the total cost of transporting, distributing, repairing, holding, purchasing and backordering of items during the planning period:

Minimize:

$$
\begin{aligned}
& c \sum_{t} \sum_{k}\left(q_{t}(k)+z_{t}(k)\right)+d \sum_{t} \sum_{k}\left(Q_{t}(k)+z_{t}(k)\right)+ \\
& a_{1} \sum_{t} x_{t}+a_{2} \sum_{t} y_{t}+h \sum_{t} D S_{t}+e \sum_{t} u_{t}+b \sum_{t} \sum_{k} B O_{t}(k)
\end{aligned}
$$

The constraints are as follows:

S. t.

$$
\begin{gathered}
F_{t}(k)+l_{t-1}(k)=q_{t}(k)+l_{t}(k) \\
Q_{t}(k)=q_{t-n}(k) \\
\Sigma_{k} Q_{t}(k)=x_{t}+y_{t} \\
X_{t}=x_{t-q} \\
Y_{t}=y_{t-p} \\
U_{t}=u_{t-l} \\
X_{t}+Y_{t}+U_{t}+D S_{t-1}=D S_{t}+S_{t} \\
S I_{t}=\Sigma_{k} z_{t}(k) \\
Z_{t+m}(k)=z_{t}(k) \\
Z_{t}(k)+B O_{t}(k)=R_{t}(k)+B O_{t-1}(k)
\end{gathered}
$$

Constraint (2) is the balance of failed items at the base. The number of failed items $q_{t}(k)$ sent from base $k$ to the in-pipeline on day $t$ plus the number of failed items $l_{t}(k)$ left unsent at base $k$ on day $t$ must be equal to the flow (the number) of all failed items $F_{t}(k)$ entering base $k$ on day $t$ plus the number of failed items $l_{t-1}(k)$ left unsent in base $k$ on day $t-1$.

Constraint $(3,10)$ is the transportation of failed (respectively good) items at the in-pipeline (out-pipeline). The flow of failed items leaving base $k$ to the depot on day $t-n$ arrives through the in-pipeline at the depot on day $t$. Where the number of good items entering the out-pipeline for base $k$ on day $t-m$ arrives at base $k$ on day $t$.

Constraint (4) is the integrating and distributing of failed items from different bases. The number of failed items entering the depot from all the bases on day $t$ is distributed between the fast and slow repair services on day $t$.

Constraints (5-6) are the repair of failed items and their "conversion" to good ones. The number of failed items $x_{t}$ (respectively, $y_{t}$ ) entering the fast (respectively, slow) service on day $t-q$ (respectively, $t-p$ ) repair service is converted into the same number of good items on day $t$.

Constraint (7) is the purchasing of a new item from an external supplier. The number $u_{t-l}$ of new items ordered from an external supplier on day $t-l$ that arrives at the depot on day $t$.

Constraint (8) is the balance of depot stock. The number of repaired items from both the fast repair service and the slow repair service on day $t$, plus the number $U_{t}$ of new items that arrived from the external supplier on day $t$, plus $D S_{\mathrm{t}-1}$ the depot stock on day $t-1$ is equal to $D S_{\mathrm{t}}$ the depot stock on day $t$ plus the number of items $S_{t}$ sent from the depot to the out-pipeline on day $t$.

Constraint (9) is the distribution of good items from 
the depot between different out-pipelines to the different bases. The total number of sent items from the depot on day $t$ is equal to the sum items $z_{t}(k)$ sent into the out-pipeline for base $k=1, \ldots, K$.

Constraint (11) is the balance of good items at the base. The number of good items $Z_{t}(k)$ transported to base $k$ from the depot through the out-pipeline on day $t$ plus $B O_{t}(k)$ the number of backordered demands at base $\mathrm{k}$ on day $\mathrm{t}$ is equal to the required number of good items $R_{t}$ on day $t$ plus the number of backordered demands at base $\mathrm{k}$ on day $t-1$.

\subsection{Network Flow Model}

Figure 2 presents a network formulation of this problem for a special case of two bases. The time parameters are given in Table 1.

\subsection{Numerical Example for the Network Flow Model}

There are two bases and the planning period is 6 days.
The requirements for good items is equal to the number of failed items thus $R_{t}(k)=F_{t}(k)$ where: $R(1)=(5-9)$ and $R(2)=(6,6,7,10,8,5)$. There is an initial stock of 15 spares at the depot. Table 1 presents the time parameters while Table 2 gives the cost parameters. The optimal result given in Table $\mathbf{3}$ is presented in Figure $\mathbf{3}$ as a network flow.

\section{Experimental Results}

\subsection{Parameters}

We present experimental results from an air force environment where airplanes are operating from three bases. Each base has 20 airplanes. The planning horizon is a 16-day wartime scenario where the planner knows the number of sorties scheduled for each base on each day during the planning horizon. This allows planners to predict the utilization rate of the airplane service for each day for each base as well as the number of flight hours that the fleet will make at each base on each day.
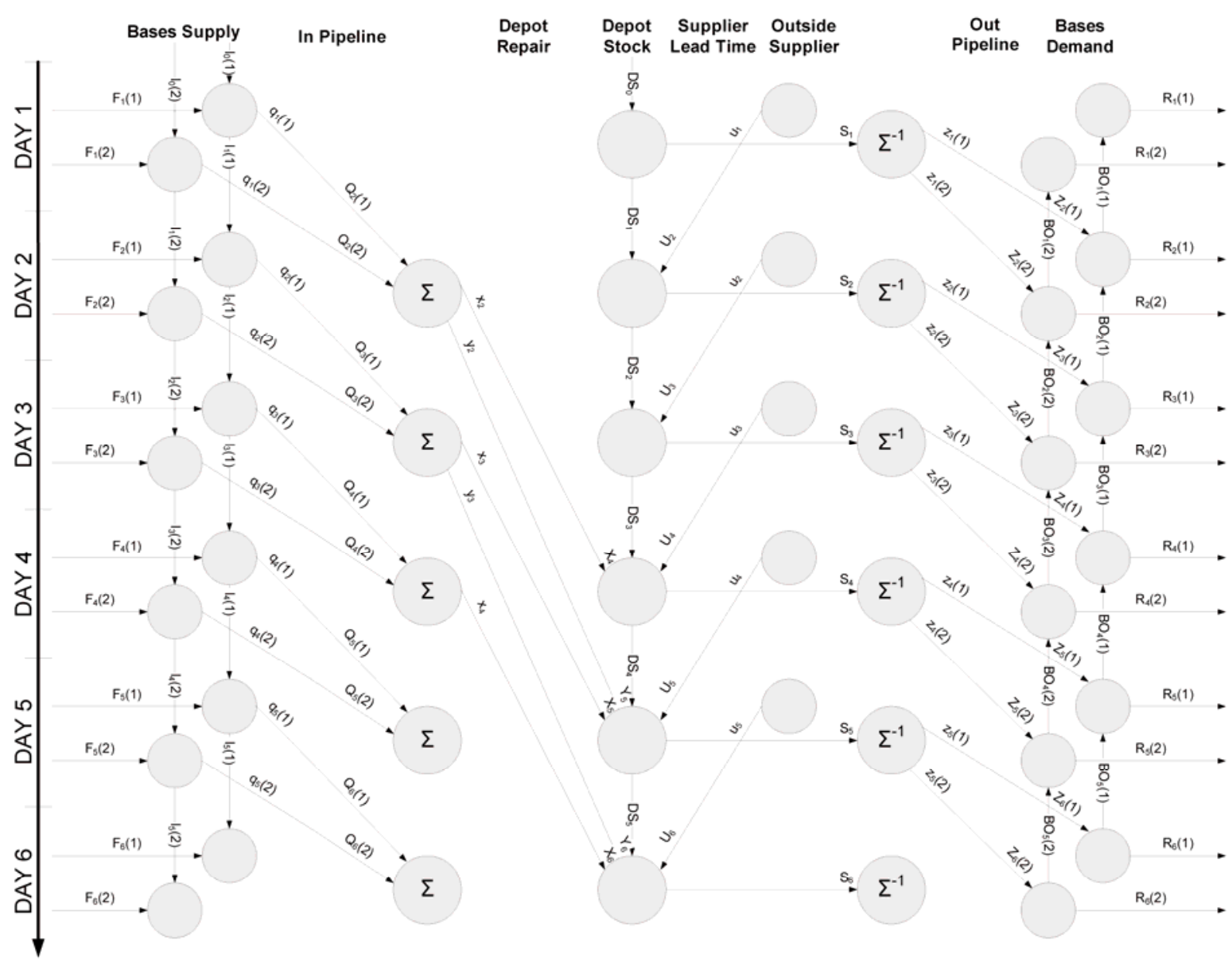

Figure 2. Network flow model. 
The unit we analyze is the airplane's air data computer. A computer backorder grounds an airplane. Given the MTBF (mean time between failures) of the computer and the flight hours planned for each aircraft, which varies from day to day depending on the war scenario, the number of failed computers for each day at each base can be predicted. Table 4 presents the number of failed computers. It is assumed that the requirement for each day equals the number of failed items. The input parameters are listed in Table 5.

\subsection{Numerical Results}

It is assumed that all parameters are known (see Table 5). The "what-if" analysis is conducted in order to study the parameters: depot initial stock, backorder penalty cost, fast service repair time and fast service cost. We list the optimal results and discuss their implications (see Tables 6-7).

Table 1. The time parameters.

\begin{tabular}{ll}
\hline \multicolumn{1}{c}{ Shipping-time at the in-pipeline } & $n=1$ days \\
\hline Shipping time at the out-pipeline & $m=1$ day \\
$\begin{array}{l}\text { Lead time from external supplier } \\
\text { to depot } \\
\text { Repair time at slow repair service }\end{array}$ & $l=1$ day \\
Repair time at fast repair service & $p=3$ days \\
\hline
\end{tabular}

Table 2. Cost data.

\begin{tabular}{ll}
\hline \multicolumn{1}{c}{ Distribution cost } & $d=0 \$$ \\
\hline Transportation cost & $c=0.05 \$$ \\
Fast repair cost & $a 1=15 \$$ \\
Slow repair cost & $a 2=10 \$$ \\
Purchase cost & $e=25 \$$ \\
Inventory holding cost & $h=0.5 \$$ \\
Backorder penalty cost & $b=40 \$$ \\
\hline
\end{tabular}

Table 3. Optimal planning.

\begin{tabular}{cccc}
\hline Day & $\begin{array}{c}\text { Number of } \\
\text { failed items to } \\
\text { enter fast repair } \\
\text { service }\end{array}$ & $\begin{array}{c}\text { Number of } \\
\text { failed items to } \\
\text { enter slow repair } \\
\text { service }\end{array}$ & $\begin{array}{c}\text { Number of items to } \\
\text { purchase from } \\
\text { external supplier }\end{array}$ \\
\hline 1 & 0 & 0 & 22 \\
3 & 9 & 2 & 18 \\
\hline
\end{tabular}

Table 4. Number of failed computers-prediction.

\begin{tabular}{cccc}
\hline & Base 1 & Base 2 & Base 3 \\
\hline Day 1 & 4 & 5 & 2 \\
Day 2 & 4 & 4 & 3 \\
Day 3 & 6 & 3 & 8 \\
Day 4 & 8 & 2 & 2 \\
Day 5 & 7 & 2 & 9 \\
Day 6 & 6 & 4 & 4 \\
Day 7 & 6 & 4 & 3 \\
Day 8 & 5 & 4 & 4 \\
Day 9 & 4 & 6 & 8 \\
Day 10 & 2 & 6 & 9 \\
Day 11 & 2 & 6 & 7 \\
Day 12 & 2 & 7 & 9 \\
Day 13 & 8 & 6 & 6 \\
Day 14 & 8 & 7 & 2 \\
Day 15 & 8 & 6 & 5 \\
Day 16 & 7 & 5 & 2 \\
\hline
\end{tabular}

Table 5. Input parameters.

\begin{tabular}{ll}
\hline \multicolumn{1}{c}{ Shipping time at the in-pipeline } & $n=1$ days \\
\hline $\begin{array}{l}\text { Shipping time at the out-pipeline } \\
\text { Lead time from external supplier }\end{array}$ & $m=1$ day \\
to depot & $l=1$ day \\
Repair time at slow repair service & $p=5$ days \\
Repair time at fast repair service & $q=3$ days \\
Distribution cost & $D=0 \$$ \\
Transportation cost & $c=0.05 \$$ \\
Fast repair cost & $A 1=15 \$$ \\
Slow repair cost & $A 2=10 \$$ \\
Purchase cost & $e=100 \$$ \\
Inventory holding cost & $h=0.5 \$$ \\
Backorder penalty cost & $B=20 \$$ \\
Initial depot stock & $D S_{0}=30 \mathrm{parts}$ \\
\hline
\end{tabular}

From Table 6 it can be seen that occasionally there are backorders. On the first day there are backorders since it takes a minimum of one day for spares to arrive from the 
Table 6. Optimal flow of items at the base.

\begin{tabular}{|c|c|c|c|c|c|c|c|c|c|c|c|c|}
\hline \multirow{2}{*}{ Day } & \multicolumn{3}{|c|}{$\begin{array}{c}\text { Failed items left unsent at } \\
\text { base } k\end{array}$} & \multicolumn{3}{|c|}{$\begin{array}{l}\text { Failed items sent to the depot } \\
\text { from base } k\end{array}$} & \multicolumn{3}{|c|}{$\begin{array}{c}\text { Good items sent from the depot } \\
\text { to base } k\end{array}$} & \multicolumn{3}{|c|}{$\begin{array}{c}\text { Backordered demands at } \\
\text { base } k\end{array}$} \\
\hline & $\mathbf{l}_{1}$ & $\mathbf{l}_{2}$ & $\mathbf{l}_{3}$ & $\mathbf{q}_{1}$ & $\mathbf{q}_{2}$ & $\mathbf{q}_{3}$ & z1 & $\mathrm{z2}$ & z3 & $\mathbf{B O}_{1}$ & $\mathbf{B O}_{2}$ & $\mathrm{BO}_{3}$ \\
\hline 1 & 0 & 0 & 2 & 4 & 5 & 0 & 8 & 9 & 5 & 4 & 5 & 2 \\
\hline 2 & 0 & 0 & 0 & 4 & 4 & 5 & 6 & 3 & 8 & 0 & 0 & 0 \\
\hline 3 & 0 & 0 & 0 & 6 & 3 & 8 & 8 & 2 & 2 & 0 & 0 & 0 \\
\hline 4 & 0 & 0 & 0 & 8 & 2 & 2 & 7 & 2 & 9 & 0 & 0 & 0 \\
\hline 5 & 0 & 1 & 0 & 7 & 1 & 9 & 6 & 4 & 4 & 0 & 0 & 0 \\
\hline 6 & 0 & 0 & 0 & 6 & 5 & 4 & 6 & 4 & 3 & 0 & 0 & 0 \\
\hline 7 & 0 & 0 & 0 & 6 & 4 & 3 & 5 & 4 & 4 & 0 & 0 & 0 \\
\hline 8 & 0 & 0 & 0 & 5 & 4 & 4 & 4 & 6 & 8 & 0 & 0 & 0 \\
\hline 9 & 0 & 0 & 0 & 4 & 6 & 8 & 2 & 6 & 9 & 0 & 0 & 0 \\
\hline 10 & 0 & 0 & 0 & 2 & 6 & 9 & 2 & 6 & 7 & 0 & 0 & 0 \\
\hline 11 & 2 & 0 & 0 & 0 & 6 & 7 & 2 & 7 & 9 & 0 & 0 & 0 \\
\hline 12 & 4 & 7 & 9 & 0 & 0 & 0 & 8 & 6 & 6 & 0 & 0 & 0 \\
\hline 13 & 12 & 13 & 15 & 0 & 0 & 0 & 8 & 7 & 6 & 0 & 0 & 0 \\
\hline 14 & 20 & 20 & 23 & 0 & 0 & 0 & 8 & 5 & 4 & 0 & 0 & 2 \\
\hline 15 & 28 & 26 & 25 & 0 & 0 & 0 & 7 & 6 & 2 & 0 & 1 & 0 \\
\hline 16 & 35 & 31 & 27 & 0 & 0 & 0 & 0 & 0 & 0 & 0 & 0 & 0 \\
\hline
\end{tabular}

Table 7. Optimal flow of items at the depot.

\begin{tabular}{|c|c|c|c|c|c|c|c|}
\hline \multirow[t]{2}{*}{ Day } & \multicolumn{2}{|c|}{$\begin{array}{c}\text { Failed items entering/exiting the fast } \\
\text { repair service }\end{array}$} & \multicolumn{2}{|c|}{$\begin{array}{l}\text { Failed items entering/exiting the slow } \\
\text { repair service }\end{array}$} & \multicolumn{2}{|c|}{$\begin{array}{c}\text { Good items or- } \\
\text { dered/arriving } \\
\text { from external supplier }\end{array}$} & \multirow{2}{*}{$\begin{array}{c}\begin{array}{c}\text { Depot stock (good } \\
\text { items) }\end{array} \\
\mathrm{DS}_{0}=30\end{array}$} \\
\hline & $\mathbf{x}$ & $\mathbf{X}$ & $\mathbf{y}$ & $\mathbf{Y}$ & $\mathbf{U}$ & $\mathbf{U}$ & \\
\hline 1 & 0 & 0 & 0 & 0 & 9 & 0 & 8 \\
\hline 2 & 5 & 0 & 4 & 0 & 12 & 9 & 0 \\
\hline 3 & 0 & 0 & 13 & 0 & 18 & 12 & 0 \\
\hline 4 & 9 & 0 & 8 & 0 & 9 & 18 & 0 \\
\hline 5 & 5 & 5 & 7 & 0 & 13 & 9 & 0 \\
\hline 6 & 9 & 0 & 8 & 0 & 0 & 13 & 0 \\
\hline 7 & 8 & 9 & 7 & 4 & 0 & 0 & 0 \\
\hline 8 & 10 & 5 & 3 & 13 & 0 & 0 & 0 \\
\hline 9 & 13 & 9 & 0 & 8 & 0 & 0 & 0 \\
\hline 10 & 18 & 8 & 0 & 7 & 0 & 0 & 0 \\
\hline 11 & 17 & 10 & 0 & 8 & 0 & 0 & 0 \\
\hline 12 & 15 & 13 & 0 & 7 & 0 & 0 & 0 \\
\hline 13 & 0 & 18 & 0 & 3 & 0 & 0 & 0 \\
\hline 14 & 0 & 17 & 0 & 0 & 0 & 0 & 0 \\
\hline 15 & 0 & 15 & 0 & 0 & 0 & 0 & 0 \\
\hline 16 & 0 & 0 & 0 & 0 & 0 & 0 & 0 \\
\hline
\end{tabular}


depot (the out-pipeline equals 1 day). On days 14 and 15 respectively. This optimal result is obtained due to the cost parameters. For example, on day 13 there are only 21 repaired items from both fast and slow services, while the total number of orders at day 14 is 23 . Thus there is a backorder of two parts. The optimal result is to maintain this backorder since the backorder penalty cost at this stage is $\$ 20$ while the cost of a new item (the only way to fill this backorder) is much higher at $\$ 100$. When the backorder penalty cost is increased, the number of backorders is reduced to zero (see the what-if analysis below). The total number of new items purchased from an external supplier is 61 parts. The total number of items repaired at the fast service is 109 parts and at the slow service 50 . This mixture is a result of both cost parameters and delay time parameters. Although fast repair service is more expensive, more items are sent to the fast service due to the need to quickly supply repaired items to fill the orders at the bases. In addition, the ratio between the cost of fast and slow repair equals 1:5. Increasing this ratio reduces the total number of items repaired in the fast service and increases the total number of items repaired at the slow service (see what-if analysis below)

\subsection{What-If Analysis}

\subsubsection{Initial Depot Stock}

Initial depot stock is the amount of stock that the air force purchases in advance and holds at the depot. There is a tradeoff between holding a high initial depot stock at the start of the planning horizon and making a mix of purchases and repairs along the planning horizon. The procurement price of this stock is often paid in advance and entails extra inventory holding costs at the depot. We study the implication of a change in initial depot stock level. In Table 8, the results show what happens when the initial depot stocks vary from 30 spares to 110 . When the initial stock rises from 30 to 91 spares, there is a reduction in spares purchased from the external supplier by the same amount. There is no change in the number of backorders and the time they occur. When the initial depot stock exceeds 91 spares there is no need to purchase parts from an external supplier. When there is a high level of initial stock, there is a change in the optimal mix of repairs. Specifically, more parts are repaired at the slow service and there are zero backorders. Thus from the point of depot stocks equaling 91, the slow service is used more than the fast service, since this service is cheaper and with high depot stock there is no need for a short repair time.

\subsubsection{Backorder Penalty Cost}

Estimating the backorder penalty cost is based on the availability target set by the air force. High backorder cost results in a small number of backorders, and vice versa. We study the effect of changing backorder costs from $\$ 20$ to $\$ 70$ and consider backorders that are nontrivial, that is, backorders that occur from the second day on (see Table 9).

Table 8. Changes in initial depot stock.

\begin{tabular}{cccccc}
\hline $\begin{array}{c}\text { Initial } \\
\text { depot } \\
\text { stock }\end{array}$ & $\begin{array}{c}\text { Total number of parts } \\
\text { repaired at fast service }\end{array}$ & $\begin{array}{c}\text { Total number of parts } \\
\text { repaired at slow service }\end{array}$ & $\begin{array}{c}\text { Total number of parts pur- } \\
\text { chased from external sup- } \\
\text { plier }\end{array}$ & $\begin{array}{c}\text { Total number of } \\
\text { backorders } \\
\text { (non-trivial) }\end{array}$ & $\begin{array}{c}\text { Objective } \\
\text { function } \\
\text { value }\end{array}$ \\
\hline 30 & 109 & 50 & 61 & 3 & 8539 \\
50 & 109 & 50 & 41 & 3 & 6554 \\
70 & 109 & 50 & 21 & 3 & 4584 \\
90 & 109 & 50 & 0 & 3 & 2628 \\
100 & 61 & 89 & 0 & 0 & 2164 \\
110 & 27 & 113 & & 0 & 1925 \\
\hline
\end{tabular}

Table 9. Changes in backorder penalty cost.

\begin{tabular}{ccccccc}
\hline $\begin{array}{c}\text { Backorder } \\
\text { penalty cost }\end{array}$ & $\begin{array}{c}\text { Total number of } \\
\text { backorders }\end{array}$ & $\begin{array}{c}\text { Number of days } \\
\text { with backorders }\end{array}$ & $\begin{array}{c}\text { Total number of } \\
\text { purchases }\end{array}$ & $\begin{array}{c}\text { Total number of } \\
\text { fast repairs }\end{array}$ & $\begin{array}{c}\text { Total number of } \\
\text { slow repairs }\end{array}$ & $\begin{array}{c}\text { Objective func- } \\
\text { tion value }\end{array}$ \\
\hline 20 & 3 & 2 & 61 & 109 & 50 & 8539 \\
30 & 3 & 2 & 61 & 109 & 50 & 8679 \\
40 & 1 & 1 & 62 & 104 & 54 & 8804 \\
50 & 1 & 1 & 62 & 104 & 54 & 8924 \\
60 & 1 & 1 & 62 & 104 & 54 & 9044 \\
70 & 0 & 0 & 63 & 99 & 58 & 9159 \\
\hline
\end{tabular}


Table 10. Changes in fast repair time.

\begin{tabular}{|c|c|c|c|c|c|c|}
\hline $\begin{array}{l}\text { Fast service } \\
\text { repair time }\end{array}$ & $\begin{array}{c}\text { Total number of } \\
\text { purchases }\end{array}$ & $\begin{array}{l}\text { Total number } \\
\text { of fast repairs }\end{array}$ & $\begin{array}{l}\text { Total number of } \\
\text { slow repairs }\end{array}$ & $\begin{array}{c}\text { Total number of } \\
\text { backorders }\end{array}$ & $\begin{array}{l}\text { Number of days } \\
\text { with backorders }\end{array}$ & $\begin{array}{l}\text { Objective func- } \\
\text { tion value }\end{array}$ \\
\hline 3 & 61 & 109 & 50 & 3 & 2 & 8539 \\
\hline 2 & 43 & 146 & 31 & 7 & 2 & 7185 \\
\hline 1 & 20 & 195 & 5 & 23 & 4 & 5680 \\
\hline
\end{tabular}

Table 11. Changes in fast repair service cost.

\begin{tabular}{cccc}
\hline $\begin{array}{c}\text { Fast repair ser- } \\
\text { vice Cost }\end{array}$ & $\begin{array}{c}\text { Total number of parts repaired } \\
\text { at fast service }\end{array}$ & $\begin{array}{c}\text { Total number of parts repaired at } \\
\text { slow service }\end{array}$ & $\begin{array}{c}\text { Total number of parts purchased from } \\
\text { external supplier }\end{array}$ \\
\hline 15 & 109 & 50 & 61 \\
20 & 104 & 54 & 62 \\
40 & 25 & 117 & 78 \\
\hline
\end{tabular}

Analyzing the results reveals that when backorder penalty costs increase, both the total number of backorders and the number of days with backorders decreases gradually and slowly. When the backorder penalty cost equals 70 , there are zero backorders. The changes in backorder costs causes minor changes in the mix of repaired and purchased parts along the planning horizon. The total number of items repaired at the fast repair service is reduced by a small amount while the total number of both new items and of repaired items at the slow repair increases by a small amount.

\subsubsection{Repair Time at the Depot Fast Service}

The repair time is effected by repair resources such as manpower and equipment that the air force allocates. Hiring extra, better qualified manpower may shorten the repair time. In studying the impact of a shorter repair time at the fast service, we reduced the fast repair time to 2 and 1 days (see Table 10). As a result, more parts are sent to repair at the fast repair service since it has become more attractive. For example, when the fast repair time equals the lead-time from an external supplier (both equal one day), and since the cost of the fast repair is much cheaper than the purchase cost, almost all the spare parts that are needed come from the fast repair service. The fact that there are more backorders when the repair time decreases is an interesting result that emerges because the depot can only repair the items that failed. Thus there are sometimes delays in getting repaired items from the fast repair service, as opposed to the external supplier who can fulfill any amount that has been ordered.

\subsubsection{Cost of the Fast Repair Service}

The ratio of the fast and slow repair services can be set by the air force as a tool to motivate and control the usage of the two repair modes. Note that these prices are also called transfer-prices. Table 11 presents the results of changing fast service costs from $\$ 15$ to $\$ 40$.

\section{Conclusions}

In this paper we studied a repairable-item multi-echelon inventory system with multiple supply alternatives: an external supplier and fast and slow repair services. We considered the demand for spare part as a deterministic demand that can be predicted for a specified horizon. During the planning horizon, demand varies dramatically over time due to a change in the utilization rate of the parts. Our network flow model allows planning the optimal number of items that need to be repaired at each repair mode and the optimal number of new items that need to be purchased from an external supplier. Our model facilitates what-if analysis with different cost parameters and delay time parameters. This analysis is useful for practical real-life situations in order to plan and control the spare parts supply chain.

\section{REFERENCES}

[1] I. J. B. F. Adan, A. Sleptchenko and G. J. J. A. N. van Houtum, "Reducing Costs of Spare Parts Supply Systems via Static Sriorities," Asia-Pacific Journal of Operational Research, Vol. 26, No. 4, 2009, pp. 559-585.

[2] W. Hausman and G. Scudder, "Priority Scheduling Rules for Repairable Inventory Systems," Management Science, Vol. 28, No. 11, 1982, pp. 1215-1232.

[3] Y. Perlman, A. Mehrez and M .Kaspi, "Setting Expediting Repair Policy in a Multi-Echelon Repairable-Item Inventory System with Limited Repair Capacity," Journal of the Operational Research Society, Vol. 52, 2001, pp. 198-209.

[4] A. Sleptchenko, M. C. van der Heijden and A. van Harten, "Using Repair Priorities to Reduce Stock Investment in Spare Part Networks," European Journal of Operations 
Research, Vol. 163, 2005, pp. 733-750.

[5] S. Minner, "Multiple-supplier Inventory Models in Supply Chain Management: A Review," International Journal of Production Economics, Vol. 81, 2003, pp. 265-279.

[6] P. K. Aggarwal and K. Moinzadeh, "Order Expedition in Multi-echelon Production/Distribution Systems," IIE Transaction, Vol. 2, No. 2, 1994, pp. 86-96.

[7] K. Moinzadeh and P. K. Aggarwal, "An Information Base multi-Echelon Inventory System with Emergency Orders," Operations Research, Vol. 45, 1997, pp. 694-701.

[8] P. Alfredsson and J. Verrijdt, "Modeling Emergency Supply Flexibility in a Two Echelon Inventory System," Management Science, Vol. 45, No. 10, 1999, pp. 14161431.

[9] R. Ganeshan, "Managing Supply Chain Inventories: A multiple Retailer, One Warehouse, Multiple Supplier Model," International Journal of Production Economics, Vol. 59, 1999, pp. 341-354.

[10] D. F. Pyke, "Priority Repair and Dispatch Policies for Repairable-Item Logistics Systems," Naval Research Logistics, Vol. 37, 1990, pp. 1-30.

[11] J. Verrijdt, I. Adan and T. de Kok, "A Tradeoff between Repair and Inventory Investment," IIE Transactions, Vol. 30, 1998, pp. 119-132.

[12] A. Sleptchenko, M. C. van der Heijden and A. van Harten, "Effect of Finite Repair Capacity in Multi-Echelon, Multi-Indenture Service Part Supply Systems," International Journal of Production Economics, Vol. 79, No. 2, 2002, pp. 209-230.

[13] Y. Perlman and M. Kaspi, "Centralized Decision of Internal Transfer-Prices with Congestion Externalities for Two Modes of Repair with Limited Repair Capacity," Journal of the Operational Research Society, Vol. 58, No. 9, 2007, pp. 1178-1184.
[14] B. Abdul-Jalbar, J. M. Gutierrez and J. Sicilia, "Single Cycle Policies for the One-Warehouse N-Retailer Inventory/Distribution System," Omega, Vol. 34, No. 5, 2006, pp. 196-208.

[15] A. Federgruen, J. Meissner and M. Tzur, "Progressive Interval Heuristics for Multi-Item Capacitated Lot Sizing Problems," Operations Research, Vol. 55, No. 3, 2007, pp. 490-502.

[16] W. Prager, "On the Caterer Problem," Management Science, Vol. 3, 1956, pp. 16-23.

[17] L. R Ford and D. R. Fulkerson, "Flows in Networks," Princeton University Press, 1962.

[18] S. I. Gass, "Linear Programming: Methods and Applications," Dover Publications, 2003.

[19] H. Lee and C. Billigton, "Material Management in Decentralized Supply Chains," Operations Research, Vol. 41, 1993, pp. 837-845.

[20] D. J. Watts and S.H. Strogatz, "Collective Dynamics of 'Small World' Networks," Nature, Vol. 393, No. 6684, 1998, pp. 440-442.

[21] X. Liu, C. Wang, X. Luo and D. Wang, "A Model and Algorithm for Outsourcing Planning," Proceedings IEEE International Conference on E-Business Engineering ICEBE'05, Beijing, 2005, pp. 1-4.

[22] X. Liu and J. Zhang, "A Capacitated Production Planning with Outsourcing: A General Model and Its Algorithm," Lecture Notes in Computer Science, Vol. 4113, 2006, pp. 997-1002.

[23] J. Zheng, "A Modeling Framework for the Planning of Strategic Supply Chains Viewed from Complex Network," Journal of Service Science\& Management, Vol. 2, No. 2, 2009, pp. 129-138. 